\title{
DOCUMENTARY FILMS - CREATING NARRATIVES OF SOCIAL CHANGE THROUGH FACTUAL STORYTELLING
}

\author{
SHIV SHANKAR DAS \\ Research Scholar, Department of Journalism \& Mass Communication,
}

Utkal University, Bhubaneswar, Odisha, India

\begin{abstract}
Documentary films have become an important channel for audiences to process and decipher information today. Having an inherent power to critically address contemporary issues in a threadbare manner, they have a cornucopia of new insights for tackling different problems plaguing our society. Higher perceptions of reality and factuality positively affect learning and engagement among the public. The genre with its claim to indexicality and veridicality has an important social function of setting the agenda by penetrating public consciousness, which in turn amplifies the sphere of civic discourse on various social issues. Good storytelling in documentary films can ignite powerful emotions and evoke empathy among its audiences. Such an impact facilitates major change in viewpoints and fuels social change. This paper has used the tool of textual analysis to examine two critically acclaimed and pivotal social issue documentaries- 'Some Stories Around Witches' made by four time national film award winner Lipika Singh Darai and 'Veil Done' filmed by Juhi Bhatt which won the national film award for the 'Best Film on Social Issues' in 2018. This will help us decipher the mechanics of factual storytelling, the cinematic devices used to infuse emotions, creating a gripping and thoughtprovoking film.
\end{abstract}

KEYWORDS: Indexicality, Veridicality, Reality, Empathy, Social Change, Factual Storytelling \& Cinematic Devices

Received: May 05, 2019; Accepted: May 25, 2019; Published: Jun 13, 2019; Paper Id.: IJCMSAUG20191

\section{INTRODUCTION}

Our notion of reality to a great extent is shaped by documentaries. They quench our thirst for unravelling and interpreting social phenomenon. By presenting authentic and organic stories, they produce awareness and behavioral outcomes. There has been a huge upsurge in production of documentary films today. Michael Moore's Fahrenheit 9/11, Morgan Spurlock's Super Size Me, and Luc Jacquet's The March of Penguins have broken the ultimate barrier by becoming box-office success. Directors from India like Mike Pandey, Anand Patwardhan, Sanjay Kak, Rakesh Sharma, Amar Kanwar and Rajiv Mehrotra, to name a few, have carved a niche for themselves on the international stage. The spectrum of documentary films is quite wide as it can be a fly on the wall observational film, a travelogue, an investigative story, animation, interactive documentary or even a documentary based video \& art installation.

Documentary films are fundamentally non-fictional, factual works based on a slice of life. As they operate in the realm of authenticity and genuineness of information, they have a profound impact on public consciousness. Wilma De Jong (2017) says "Documentary is best described as a hybrid film genre which attempts to represent the real in a creative and critical art form”. Providing a comprehensive description of the genre, Caty Borum Chattoo (2018) remarks that "Documentary is a mediated storytelling genre and communication practice shaped by the 
creative freedom of scripted entertainment storytelling, alongside aspects of the research, reporting practices, and outputs of journalism. Documentary, therefore, is both an artistic expression and product, as well as reflection of truth. In this context, it can also be understood as a mechanism for communication in pursuit of social change and engagement with the public about topical issues. Documentary storytelling in the United States and around the world is often produced by independent filmmakers who are external to the decision-making boundaries of formal media institutions. Independence permits often-unseen perspectives to be reflected in the culture and enables community-centered storytellers and collaboration. Documentary production practices and audience accessibility have evolved in the digital era and consequently so has the potential for nonfiction storytelling to actively engage publics. As contemporary audiences are able to access documentaries in theaters, TV, online streaming outlets, and social media channels, documentary storytelling plays an influential persuasive role, shaping public opinion and spotlighting social issues. Documentary is often leveraged as an advocacy communication mechanism to raise awareness and advocate for change on challenging social problems and issues".

To understand and analyze documentary films, Bill Nichols (2010) provides the five modes of documentary representation. The first mode is expository in which the films directly address the viewer. They produce an argument about the occurrences which helps solve the problem. In the observational mode, there is a direct representation of life as seen through the camera. There is interaction between the filmmaker and subject through interviews in the interactive mode. Here the filmmaker overtly participates with the subject in examination of the issue. Reflexive mode makes an analysis of the process of representation through the documentary convention. The final mode which is termed as performative emphasizes on emotional impact of documentary films on audience. Techniques associated with fiction films such as restaged events or edited montages are used.

Reality is not found in a structured way. The fragmented parts have to be put together for coherence. Therefore, non-fictions use a well thought out narrative and filmic elements to document it. The construction of social reality and its presentation in the mode of factual storytelling evokes compelling emotional reactions from the audience. They use evidence, definite argument, associative connections between occurrences, dramatic reconstruction and intervention by the filmmaker while interpreting reality.

In the study - The State of the Documentary Field: 2018 by Caty Borum Chattoo and William Harder states that "The evolving digital era presents new opportunities for documentary makers and audiences as platforms shift, new storytellers emerge and media systems transform. Documentary has long enjoyed a vibrant space in the media ecology, and the marketplace for creative nonfiction storytelling continues to expand. Although the digital age began in the latter part of the $20^{\text {th }}$ century, its practical implications have manifested for documentary storytellers and fans within the last 10-15 years-the era of You Tube, social media, streaming networks and accessible filmmaking equipment. Audiences are finding nonfiction stories in new ways, organizations have emerged at the intersection of documentary and public engagement, and a global community of documentary filmmakers continues to grow".

The raison de'tre of non-fiction films is providing platforms for representing the disenfranchised and giving voice to the voiceless. At its heart lies the philosophy of empowerment and increasing the proximity between the referent and representation. Within documentary, it is the indexical that provides a basis for social action. Bill Nichols (2017) says "Indexical documentation is one of the four foundational stones for documentary film (together with narrative story-telling, poetic experimentation, and rhetorical tradition of oratory). It conveys a sense of the stickiness of reality, fixing photo- 
graphic representations within a specific time and place, and hence, a sense of authenticity around photographic evidence. (Nichols 1991)

As documentaries are primarily indexical, ethical criteria is stringent in this category. A unique bond between the film and its viewer is created because of the ethical appropriateness. As films with evidential value, they have evolved into powerful instruments for investigating complex and controversial social issues. But with it comes the responsibility of following a set of credo that has public good as its guiding principle. Verdicality is another component which gives documentaries a kind of intellectual authority. Carl Platinga (2005) says "In a documentary, what the filmmaker asserts, in the first instance, is that the images, sounds, and other materials are presented are what I will call veridical representations of whatever the documentary takes as its subject. Photographic and sonic communication in the documentary require that we consider the notion of asserted veridical representation (AVR) as embedded in our concept of the typical or usual documentary".

Non-fiction films deal with diverse issues such as agriculture, sustainable development, environment, livelihood, conflict, health, gender, governance, education, human rights wildlife, music, arts \& crafts, public diplomacy, biography, religion \& spirituality, literature, urbanization, globalization and many more. As Shiela Curran Bernard (2007), remarks "A good documentary confounds our expectations, pushes boundaries, and takes us into worlds-both literal worlds and world of ideas- that we did not anticipate entering".

Compelling, authentic and timely stories add a new perspective or dimension to a critical social issue. Based on facts, they inform and guide viewers about political, economic and social issues for constructive participation in the democratic set-up. Dictated more by substance than style, their pragmatic story construction leads viewers to definite conclusions.

\section{DOCUMENTARY FILMS AS INSTRUMENT OF SOCIAL CHANGE}

Social change entails removal of structural inequalities, societal norms and cultural practice that act as stumbling block in the path of emancipation of people. The power of visual story telling lies in its ability to leave strong imprints in the psyche of the audience by providing an interpretative frame for decoding social affairs. Enumerating the functions attributed to documentary films, Michael Renov (1993) terms them the 'four fundamental tendencies' which are 1. to record, reveal, or preserve2. to persuade or promote3. to analyze or interrogate4. to express. Acting as a looking glass, it can take the role of a catalyst for collaboration, dialogue and brainstorming among the stakeholders and lay the foundation of social change. Visual storytelling can be used as a lever to improve the lives of the most vulnerable.

Storytelling is the key to success of documentary films. It is about empowering people through the process. In the narrative, negativity is not always the hook, rather it is about effective solutions to shared problems and success stories of engaged citizens. This has much resonance with the audience. As a storyteller who is active and concerned, the filmmaker takes the audience through a journey of awareness. Good storytelling in documentary films can ignite powerful emotions and evoke empathy among its audiences. Highlighting this Plantinga (2009) says: "In movie spectatorship as in the rest of life, the repetition of elicited emotions and judgements may solidify ways of thinking and feeling. It is through the elicitation of emotion in relation to moral and ideological judgement that a film may have its most significant ideological force". 
The amalgamation of telling stories that matter and solutions that are enduring, makes it a potent tool in generating lasting change. Such films can be powerful amplifiers for dissemination of best practices for ushering in collective transformation of the citizenry. There is strong evidence that audiences perceive documentary films to be more realistic than fictions. In the research conducted by Heather L. LaMarre and Kirsten D. Landreville (2009), they report that because of their perceived realism, documentaries when compared to fictional films generate more engagement at the emotional level in relation to issue interest and learning as real footage, real people and no scripts are used for presentation of historical material. Further, they emphasize on the critical role narrative quality has on engagement and perceived realism. Thus, the persuasive powers of non-fiction films can be harnessed for inducing civic action.

\section{'SOME STORIES AROUND WITCHES' AND 'VEIL DONE' - TEXTUAL ANALYSIS AND MEANING-MAKING}

Textual Analysis as a tool is useful for researchers working in media studies, cultural studies and sociology. Fundamentally an interpretation of texts (films, television program, advertisements and so on), it is applied in order to find out how people interpret reality around them and their sense- making practice. The purpose is to describe content, structure and functions of the messages contained in texts. When we read a moving image text (such as film or television), we look at the form and the content, as well as the camera movement, sound and the editing (the way the film is put together). (Bainbridge, 2015)

Textual analysis of a documentary film involves observing and analyzing all the filmic elements such as narration, camera angles, sound and sequencing that create meaning for the film. It also involves understanding how film fits into the historical, socio-cultural and political environment. Thus, leading to a thorough investigation of the film and the impact it creates on the audience. As meaning-making mechanism, it furthers our insight into the craft of non-fiction films.

'Some Stories Around Witches', an interactive and performative mode documentary, directed by the four time national film award winner Lipika Singh Darai, puts the focus light on heart rending stories of people from Mayurbhanj and Keonjhar districts of Odisha whose lives have been destroyed by the abominable and heinous practice of witch hunting. Produced by PSBT (Public Service Broadcasting Trust), the fifty-three minute long film in Odia with English subtitles is based on three cases titled- Niru, The Electric Pole and Chicken Meal. All three of them delve into the crux of such a pervading social evil.

In narrative terms, a striking feature of this documentary is that the director has shunned overarching arguments. Rather it is the sequences and situations that speak of the intricacies and nuances of social life in remotest places of our country. This helps the audience ponder and draw their own conclusion. Niru- the first case is about a juvenile girl who beheads an old woman, her sister's mother-in-law, who she believed had killed her father through black magic practice. Electric pole-the second case tells the story of a woman who was labelled a witch. Stripped and tied to an electric pole, she was thrashed mercilessly by the villagers. Chicken Meal - the last case enumerates the ordeal of a particular family who are accused of indulging in sorcery as they did not adhere to the diktat of community members and consumed chicken meat during the period of ongoing religious rituals in the village. Fined twenty thousand rupees, they were ostracized by the villagers. The film also captures the traumatic and harrowing experience of a five year old girl Moumita who was thrown out of school as she was accused of turning into a blood sucking cat.

The poignant images such as Niru's vacant look and the inability to fathom why she indulged in such a gruesome act, the looks of desperation and tears swelling in the eyes of the old couple suspected of practicing black magic, who are 
now forced to take refuge at an old age home fearing a backlash from their relatives, the palpable fear and desperation prevalent in the ostracized family and the deep scar in the psyche of the five year old brings to light the stark realities resultant of toxic blind beliefs. Ignored by the mainstream media and rarely a part of their discourse, basic services like education, medical facilities or transport system are virtually non-existent in these villages. This provides a breeding ground for the deep rooted belief in black magic. Despite the enactment of Odisha Prevention of Witch-Hunting Act in 2013, such practices are rampant. Such a barbaric practice has to be tackled head on through an aggressive awareness and socioeconomic interventions for the affected communities.

An investigative documentary, the analysis of its audio-visual strategies for constructing the story reveals that it is somber in terms of visuals and does not veer away from the harsh ground realities. The subtle camera work, interspersed with wide-angle shots of the locale, medium shots and close-ups of the people, helps the viewer build a perspective. Putting the subject right in the middle of the frame, the sole focus is on the theme. This makes it a very effective technique in impactful storytelling as the audience is transported to such far-flung areas presented on-screen and connects with them at an emotional level. This leads to generation of empathy among the viewers. Using voice-over, the director brings out the linkage among the cases. Drawing on her experience, she narrates how her mother's family was boycotted on baseless allegations of practicing sorcery. The visual representation uses ideational montages for progression of ideas. This firmly positions the viewer in the story as it not only shows but gives evidence too. All these help juxtapose the different facets into a unified one which culminates in a comprehensive account of the vexing social problem.

Veil Done, an expository and performative mode documentary, directed by Juhi Bhatt, captures the travail of three women who fight against all odds which seemed unsurmountable and win their right to exercise for physical fitness and mental well-being. The thirty minute film in Hindi with English subtitles and produced by PSBT(Public Service Broadcasting Trust), won the National Film Award for the 'Best Film on Social Issues' in 2018.

From the narrative perspective, it follows a monomyth approach to storytelling where the protagonists wage a battle against social proscription and at the end come out as winner. The film is a grim reminder of the reality that good health and fitness can be an arduous pursuit for women in India who are bogged down by noxious traditions and burgeoning daily chores. Living in Delhi's Nizamuddin East Basti, Afroz Jamala, Mehru Nisha and Shah Jahan were bereft of any decision making power as regards their course of life. First it was their parents and then after marriage it is the inlaws and husbands who dominated them. Sharing their woes, helplessness and predicament, Jamala tells that she was good in sports like Kho-Kho and Kabaddi. She might have become the national champion but for her father who did not allow her to play. Mehru Nisha was yearning to break free from the restrictive social environment which was suffocating her and Shah Jahan who was body shamed for being overweight. The three are angry and frustrated as their terms of living are dictated by their respective family members. Shackled by the chains of patriarchy, it seemed that they had lost their voice and individuality. But their life took a turn for the better when Mehru Nisha and Shah Jahan join a government run free gymnasium in their locality while Jamala goes to an open gym. The story of Vimlesh, the instructor of the gymnasium also resonates with theirs too. Fighting against male oppression and insinuations, she has been running the gym with grit and gumption. All the four stories are intertwined where the veil is seen as an instrument of subjugation. But their will power and the gym, acting as a catalyst for enhancing their self-esteem, fuels their resistance. Occupying the space- the gym, a traditional male bastion, is no mean feat. Renegotiating their identities through a self-fulfilling prophecy, it is a path they believe can lead to their self-actualization. The metamorphosis of the three women into having confident feelings about 
themselves culminates in the shot towards the end when a hesitant Mehru Nissa removes her veil in public to enjoy a glass of juice. To this, the film says 'Well Done'.

The visual play of the film uses the epistemic power of the images to draw attention of the viewer towards the story being presented. The simple shot which is fundamentally a basic frame and contains one subject has been used effectively in the documentary for creating and maintaining identification with the characters. To augment this, medium shots of the subjects brings in believability as the audience gets the information directly from the 'talking-head'. Along with use of indirect interview techniques where they speak directly to the viewers, close-ups that zoom in, focusing on the face of the subject puts the viewer in the same emotional state as the subject. This helps develop intimacy with the characters. For transferring information and advancement of ideas, evidentiary editing which Bill Nichols (2001) states as "a practice in which expositional images illustrate, illuminate, evoke, or act in counterpoint to what is said. We take our cue from the commentary and understand the images as evidence or demonstration", has been used in the documentary. All these function as tools to strengthen the spoken narrative.

\section{CONCLUSIONS}

The documentary film genre deconstructs and interrogates the issues through realism and authentic testimony. Visual associations bring about critical engagement. Authentic and timely stories add a new perspective or new information to a critical social issue. The documentary has a kind of intellectual authority as a serious genre in film. The most ethical form of filmmaking, there is something pure and honest about documentary film. Actuality media leverages its ordered presentation of story elements and logical narrative for the desired emotional appeal. Storytelling perspective and audio-visual pattern in the film has a direct bearing on the degree of coherence and emotionality.

In his book, Moving Viewers (2009), Carl Plantinga presents this line of thinking: "Why have effect and emotion in film viewing received relatively little attention in film studies. A strong strain of Western thought has considered emotion to be antithetical to reason and an obstacle to critical thinking. Emotions are intimately tied to our cognition, inferences, evaluations and all of the other mental activities that accompany the viewing experience. Emotions and effects have implication for ideas, they play a role in the creation of both cultural and individual memory".

The films 'Some Stories Around Witches' and 'Veil Done' utilize factual evidence, narration, arguments, interviews and audio-visual style for exploring reality. Being the viewer's eyes, the camera shots raise the level of response among the audience and sets the mood and tone of the audio-visual communication. These elements work on the cognitive and the emotional dimension of the audience. This synthesis of cognition and emotion appeals to the viewer's imagination and leads to character identification. The thesis of the documentaries is proved by credible and compelling portrayal of the social issues. The powerful story arc reorients and furnishes a holistic viewpoint on the critical problems while interweaving of the scenes and moments in a non-linear form creates meaning. Placed in an explicit discursive context, they articulate a broader argument and submit a new conception about the issue. 


\section{REFERENCES}

1. Jong, W. D., Knudsen, E., \& Rothwell, J. (2014). Creative Documentary: Theory and Practice. Florence: Taylor and Francis.

2. Nichols, B. (2010). Introduction to documentary. Bloomington, IN: Indiana University Press.

3. Bernard, S. C. (2010). Documentary storytelling: Creative Nonfiction on Screen. Oxford (England): Focal Press.

4. Elasri, K. A Linguistic And Cultural Analysis Of Sympathy, Compassion, Empathy And Pity In English And Moroccan Arabic.

5. The State of The Documentary Field: 2018 Study of Documentary Professionals. (n.d.). Retrieved from http://cmsimpact.org/report/state-documentary-field-2018-study-documentary-professionals/

6. Plantinga, C. (2005). What a Documentary Is, After All. The Journal of Aesthetics and Art Criticism, 63(2), $105-117$. doi:10.1111/j.0021-8529.2005.00188.x

7. Renov, M. (1993). Theorizing Documentary. New York:Routledge.

8. Shivraj, P., \& Philip, H. (2016). Role of mass media in changing awareness level on climate change among small and marginal paddy farmers of Tamil Nadu. Int J Humanities and Soc Sci Interventions, 5(4), 45-50.

9. Plantinga, C. (2009). Moving viewers: American film and the spectators experience. Berkeley, CA: University of California Press.

10. Lamarre, H. L., \& Landreville, K. D. (2009). When is Fiction as Good as Fact? Comparing the Influence of Documentary and Historical Reenactment Films on Engagement, Affect, Issue Interest, and Learning. Mass Communication and Society, 12(4), 537-555. doi:10.1080/15205430903237915

11. Bainbridge, J., Goc, N., \& Tynan, L. (2015). Media and journalism: New approaches to theory and practice. Victoria: Oxford University Press.

12. Harindranath, R. (2009). Audience-citizens: The media, public knowledge and interpretive practice. New Delhi: SAGE Publications.

13. Chatterji, S. A. (2015). Filming reality: The independent documentary movement in India. New Delhi: SAGE Publications.

14. PSBT India. (2018, August 30). SOME STORIES AROUND WITCHES.[Video File]. Retrieved from https://www.youtube.com/watch? $v=v X o D z I V 9 U F c$

15. DD News. (2017, August 20). VEIL DONE. [Video File]. Retrieved from https://www.youtube.com/watch?v=c5DyGwMXX9I 
